\title{
Potential changes in number of generations of oriental fruit fly, Bactrocera Dorsalis (Diptera: Tephritidae) on mango in India in response to climate change scenarios
}

\author{
JAIPAL S. CHOUDHARY ${ }^{1}$, M. SRINIVASA RAO ${ }^{2}$, SANTOSH S. MALI ${ }^{1}$, BIKASH DAS ${ }^{1}$, ANJALI \\ KUMARI, DEBU MUKHERJEE ${ }^{1}$, A. K. SINGH ${ }^{1}$ and B. P. BHATT ${ }^{3}$ \\ ${ }^{1}$ ICAR Research Complex for Eastern Region, Research Centre, Plandu, Ranchi-834010 (Jharkhand) India. \\ ${ }^{2}$ Central Research Institute for Dryland Agriculture (CRIDA) Santoshnagar, Saidabad PO Hyderabad-500 059, \\ ${ }^{3} I C A R$ Research Complex for Eastern Region, ICAR Parisar, P. O. Bihar Veterinary College, Patna- 800014 (Bihar) \\ *Corresponding Author: Email: choudhary.jaipal@gmail.com
}

\begin{abstract}
The oriental fruit fly, Bactrocera dorsalis (Hendel) is a major pest of mango crop in India and the present studies conducted to estimate the number of generations in relation to changing temperature on mango fruits across eight different geographically isolated major mango growing locations of India. The prediction of insect pest generations and generation time was done for baseline (1961 to 1990), present (1969 to 2005), near future (2021 to 2050) and distant future (2071 to 2098) periods using A1B emission scenario data from the regional circulation model (RCM), Providing Regional Climates for Impacts Studies (PRECIS) model. The degree days models using minimum and maximum temperature were used to obtain cumulative degree days (DD) for each generation of $B$. dorsalis using a temperature threshold of $13^{\circ} \mathrm{C}$. It was estimated that faster accumulation of degree days would make possible for occurrence of one or two additional generations with shortened mean life cycle (5 to 7 days less) in near and distant future climate change periods compared to baseline and present periods at majority of locations. Increased number of generations and reduction of generation time at majority of mango growing locations of India suggest that the incidence of $B$. dorsalis may likely to increase due to projected increase in temperatures during future climate change scenarios.
\end{abstract}

Key Words : Mango, B. dorsalis, climate change scenarios, degree days, generation time, generations

Global temperatures have increased by $0.78^{\circ} \mathrm{C}\left(0.72^{\circ} \mathrm{C}\right.$ to $0.85^{\circ} \mathrm{C}$ ) between the average of the $1850-1990$ periods and future increase predicted by 2100 was set at $1.8-4^{\circ} \mathrm{C}$ (IPCC, 2013). Future predictions of temperatures are varying with models and emission scenarios and extent of increase is expected to be varying across geographical locations. Climate change projections made for India indicate an overall increase in temperature by $2-4^{\circ} \mathrm{C}$ and precipitation by $9-$ $16 \%$ towards 2050s (Krishna Kumar et al., 2011). Annual mean temperature data analysis for period 1901 to 2005 by India meteorological department (IMD) evidenced for an increase of $0.51^{\circ} \mathrm{C}$ temperature during the period. This increased temperature is mainly due to increase in maximum temperature over a large part across the country (Srinivasa Rao et al., 2014b).

Being poikilothermic organisms, the developmental rate in insects is highly dependent on external temperature conditions. Hence, temperature is normally considered the single most significant environmental factor influencing behaviour, distribution, development, survival and reproduction in insects. Knowledge on the temperaturedependent population growth potential of insect pests is highly essential for understanding their population dynamics and for implementing region specific pest control strategies, especiallyin the context of predicted global warming (Briere et al., 1999; Jarvis and Baker, 2001). Each and every insect has its own 'threshold temperature' ranges within which its development occurs (Srinivasa Rao et al., 2015). So, increased temperatures will accelerate the development of insects, possibly leads to more generations (and crop damage) per year. More number of generations means an increase in the number of reproductive events per year and it would ultimately influence the intensity of crop-insect interactions (Yamamura and Yokozawa, 2002). Growing degree day (GDD) is a measure of the amount of heat that accumulates above a specified base temperature during a $24 \mathrm{~h}$ period and it is a valuable tool for predicting pest activity.

India is the highest mango producer in the world and also has the richest collection of mango cultivars and ranks first among mango producing countries accounting for 50 
Table 1: Details of locations, period considered and annual temperature variations over the base line period for probable infestation of B. dorsalis on mango in particular region of India

\begin{tabular}{|c|c|c|c|c|c|c|c|c|c|}
\hline \multirow{3}{*}{$\begin{array}{l}\text { Location } \\
\text { (State) }\end{array}$} & \multirow{3}{*}{$\begin{array}{l}\text { Latitude } \\
\left({ }^{\circ} \mathrm{N}\right)\end{array}$} & \multirow{3}{*}{$\begin{array}{l}\text { Longitude } \\
\left({ }^{\circ} \mathrm{E}\right)\end{array}$} & \multirow{3}{*}{$\begin{array}{c}\text { Period } \\
\text { considered } \\
(\mathrm{SMW}) \\
\end{array}$} & \multicolumn{6}{|c|}{ Temperature variation over base line } \\
\hline & & & & \multicolumn{2}{|c|}{ PR period } & \multicolumn{2}{|c|}{ NF period } & \multicolumn{2}{|c|}{ DF period } \\
\hline & & & & Tmax & Tmin & Tmax & Tmin & Tmax & Tmin \\
\hline Paria (Gujarat) & $20^{\circ} 50^{\prime}$ & $73^{\circ} 14^{\prime}$ & $9^{\text {th }}-30^{\text {th }}$ & 1.46 & 0.11 & 1.71 & 2.20 & 3.10 & 4.35 \\
\hline Vengurle (Maharashtra) & $15^{\circ} 85^{\prime}$ & $73^{\circ} 63^{\prime}$ & $4^{\text {nd }}-25^{\text {th }}$ & 1.78 & -0.11 & 1.64 & 1.89 & 3.14 & 3.93 \\
\hline Lucknow (Uttar Pradesh) & $26^{\circ} 85^{\prime}$ & $80^{\circ} 94^{\prime}$ & $12^{\text {th }}-33^{\text {th }}$ & 1.49 & -0.55 & 1.78 & 2.00 & 4.69 & 4.57 \\
\hline Sangareddy (Telangana) & $17^{\circ} 61^{\prime}$ & $78^{\circ} 08^{\prime}$ & $11^{\text {th }}-32^{\text {th }}$ & 1.38 & 0.5 & 1.85 & 2.19 & 3.69 & 4.57 \\
\hline Bhubaneswar(Odisha) & $20^{\circ} 29^{\prime}$ & $85^{\circ} 82^{\prime}$ & $4^{\text {nd }}-25^{\text {th }}$ & 0.07 & 1.99 & 1.62 & 3.87 & 3.88 & 4.11 \\
\hline Ranchi (Jharkhand) & $23^{\circ} 34^{\prime}$ & $85^{\circ} 30^{\prime}$ & $12^{\text {th }}-33^{\text {th }}$ & 1.00 & 0.11 & 2.05 & 2.02 & 4.46 & 4.63 \\
\hline Bengaluru (Karnataka) & $12^{\circ} 97^{\prime}$ & $77^{\circ} 59^{\prime}$ & $12^{\text {th }}-33^{\text {th }}$ & 0.17 & 0.71 & 2.08 & 2.06 & 4.01 & 4.36 \\
\hline Mohanpur (West Bengal) & $21^{\circ} 84^{\prime}$ & $87^{\circ} 42^{\prime}$ & $12^{\text {th }}-33^{\text {th }}$ & 0.28 & 0.97 & 2.11 & 2.01 & 4.59 & 4.55 \\
\hline
\end{tabular}

per cent of the world's production. The oriental fruit fly, Bactrocera dorsalis (Hendel) is a polyphagous and destructive insect pest of mango fruits which causes yield losses ranging from 5 to 80 per cent (Stonehouse, 2001). Presently, it has been recorded throughout South, South East, Far East Asia and some pacific islands including Hawaii and recently its widespread presence was reported from many countries of African continent (Kapoor 1993; Choudhary et al., 2016). With its broad host range, short life cycle, high mobility and high fecundity, B. dorsalis population growth is expected to respond strongly to temperature changes.

Considering the importance of mango and the $B$. dorsalis, present study is aimed to understand the climate change particularly increased temperature effects on number of generations of $B$. dorsalis using degree-day models on mango fruits considering four time periods (base line, present, near future and distant future) of eight major mango production locations of India.

\section{MATERIALS AND METHODS}

\section{Weather data}

In present study, we considered four climatic time periods viz., base line (BL, 1961 to 1990), present period (PR, 1969 to 2005), near future (NF, 2021 to 2050) and distant future (DF, 2071 to 2098) to collect the daily minimum and maximum temperatures. Historical daily temperatures for eight study locations (Table 1) were collected from a $1 \mathrm{X} 1^{\circ}$ grid database provided by IMD.

For future temperature data, we developed the projections obtained at a resolution of $50 \times 50 \mathrm{~km}$ grid using PRECIS, where the daily data on maximum temperature, minimum temperature and rainfall are available for the period 1961 to 2098. The A1B scenario is the most appropriate scenario for simulating the monsoon climate over India and characterized by rapid economic growth, quick expansion of new and efficient technology, moderate population growth and balanced use of energy sources. The future temperatures obtained were classified near future (NF, 2021 to 2050) and distant future (DF, 2071 to 2098) as followed earlier Srinivasa Rao et al. (2014b).

The selection of period for predicting the number of generations and generation time of $B$. dorsalis on mango was considered based on fruiting of mango across the selected region. The details of locations and period for $B$. dorsalis probable infestation are given in Table 1. The probability of $B$. dorsalis infestation on mango in particular area comprises mainly $145-150$ days due to staggered flowering in selected region.

\section{Degree-day model and number of generation}

Degree-day models ‘ingen' software (Srinivasa Rao et al., 2014a) downloaded from ICAR-NICRA (National Innovations in Climate Resilient Agriculture) (www.nicra.in)were used to calculate the generation number and generation time. This software is developed to estimate the number of insect generations using degree day approach on maximum and minimum temperature (Tmax and Tmin) data for a given temperature threshold specific to the insect following the horizontal cut-off (degree day accumulations above the upper threshold do not count) method. Detailed information on this software can be found in Srinivasa Rao et al. (2014a). In the present study, the number of generations of $B$. dorsalis was estimated using lower threshold temperature of $13.0^{\circ} \mathrm{C}$ (Stephens et al., 2007). The number of degree days 
Table 2: Variation in number of generations (mean \pm standard deviation) of $B$. dorsalis at mango fruiting season in eight major mango growing regions of India under A1B climate change scenario.

\begin{tabular}{lccccc}
\hline Name of location & \multicolumn{2}{c}{ Current climate situation } & & \multicolumn{2}{c}{ Future climate change situation } \\
\cline { 2 - 3 } \cline { 5 - 6 } & Base line period & Present period & & Near future period & Distant future period \\
\hline Paria & $4.69 \pm 0.20(-3.88)^{* *}$ & $4.84 \pm 0.11$ & & $5.22 \pm 0.19(9.50)^{* *}$ & $5.75 \pm 0.21(23.80)^{* *}$ \\
Vengurle & $4.30 \pm 0.17(-2.23)^{\mathrm{NS}}$ & $4.39 \pm 0.12$ & & $4.80 \pm 0.17(10.76)^{* *}$ & $5.38 \pm 0.16(34.17)^{* *}$ \\
Lucknow & $5.95 \pm 0.34(9.37)^{* *}$ & $5.34 \pm 0.19$ & & $6.52 \pm 0.36(16.45)^{* *}$ & $7.20 \pm 0.32(23.74)^{* *}$ \\
Sangareddy & $5.08 \pm 0.23(-3.66)^{* *}$ & $5.25 \pm 3.56$ & & $5.61 \pm 0.29(6.22)^{* *}$ & $6.31 \pm 0.31(17.12)^{* *}$ \\
Bhubaneswar & $5.54 \pm 0.33(15.56)^{* *}$ & $4.54 \pm 0.15$ & & $6.07 \pm 0.40(21.22)^{* *}$ & $6.74 \pm 0.29(35.25)^{* *}$ \\
Ranchi & $5.36 \pm 0.37(6.35)^{* *}$ & $4.91 \pm 0.18$ & & $5.87 \pm 0.40(12.60)^{* *}$ & $6.52 \pm 0.31(21.87)^{* *}$ \\
Bengaluru & $4.12 \pm 0.28(-2.60)^{\mathrm{NS}}$ & $4.24 \pm 0.11$ & & $4.72 \pm 0.28(8.81)^{* *}$ & $5.40 \pm 0.28(21.54)^{* *}$ \\
Mohanpur & $5.64 \pm 0.36(10.08)^{* *}$ & $4.98 \pm 0.14$ & & $6.14 \pm 0.40(16.41)^{* *}$ & $6.77 \pm 0.31(27.39)^{* *}$ \\
\hline
\end{tabular}

** Statistically significant over the present period at $p<0.01$ level and NS, not significant; Values in parenthesis are ' $t$ ' values when compared over present period.

required for completing life cycle of $B$. dorsalis (egg to adult) was taken as 470 degree days (Stephens et al., 2007). Degree-day models need a calendar start date after which degree-days begin accumulating and an end date after which degree-days stop accumulating (Ziter et al., 2012). Number of generations and generation time of $B$. dorsalis during mango fruiting was estimated in four climate periods including two future periods across major mango growing locations.

\section{Statistical analysis}

The data on mean number of generations of $B$. dorsalis over the present period for base, near future and distant future periods were compared using two-sample ttest assuming equal variances. The models are deterministic; therefore, it was not necessary to use ANOVA to make statistical inferences (Ziter et al., 2012). A non-parametric statistical test Mann-Kendall test was used for the analysis of trend in insect generations in time series for the four specified periods. The Mann-Kendall test confirm the existence of a positive or negative trend for a given confidence level (Kendall, 1975). Magnitude of trend in insect generations in time series (change per unit time) was estimated and determined by Theil-Sen's slope estimator. Statistical analysis were done by using SPSS version 21.0, Past version 3 and MAKESENS version 1.0.

\section{RESULTS AND DISCUSSION}

Significant variation in generation time and number of generations of $B$. dorsalis was observed across eight locations of India with AIB emission scenario in different time periods during mango fruiting season (Table 2). $B$. dorsalis accumulated lowest thermal degree days of 1937.89 DD with 4.24 generations at Bengaluru in comparison to highest 2509.42 DD with 5.34 generations at Lucknow during the present period (Table $2 \& 3$ ). The mean growing degree days of $B$. dorsalis was in range of $470 \pm 0.30 \mathrm{DD}$ as the units that have not changed with locations. At Lucknow, the possible number of generations is expected to increase from 5.34 under the present scenario to 7.20 under distant future scenario. The number of degree days is expected to increase 3065.08 DD during near future and 3382.49 DD during distant future making it to possible the complete two more additional generations as compared to the current climatic conditions at Lucknow (2509.42 DD). Similar situation is also predicted for other locations also, where one or two more generation over four to five generations would be expected to occur during near and distant future climate change scenarios as compared to base line and present periods on mango crop in major mango growing regions of India. Increase in number of generations of $B$. dorsalis with shortened generation time over base line period was predicted to occur in near and distant future periods (Table $2 \& 3$ ). The average length of time to complete life cycle of $B$. dorsalis at Sangareddy was recorded to be 25 and 23 days during near and distant future compared to 27 and 26 days during the base level and present climatic periods, respectively. The similar decrease in generation time is marked across the other locations also (Table 3 ). The increased number of generations is obviously due to shortening of the time taken to complete a generation for the insect made possible by faster accumulation of required heat units (Srinivasa Rao et al., 2014b). Generation time is expected to be shortened by 
Table 3: Mean generation time and total accumulated degree days (TDD) of B. dorsalis at mango fruiting season in major mango growing regions of India under A1B climate change scenario

\begin{tabular}{|c|c|c|c|c|c|c|}
\hline \multirow{2}{*}{$\begin{array}{l}\text { Name of } \\
\text { location }\end{array}$} & \multicolumn{3}{|c|}{ Base line period } & \multicolumn{3}{|c|}{ Present period } \\
\hline & Mean GT & Mean GDD & TDD & Mean GT & Mean GDD & TDD \\
\hline Paria & $30.61 \pm 4.19$ & $470.11 \pm 0.24$ & $2203.44 \pm 92.91$ & $28.91 \pm 2.78$ & $470.00 \pm 0.29$ & $2276.34 \pm 51.56$ \\
\hline Lucknow & $23.79 \pm 4.30$ & $470.00 \pm 0.23$ & $2794.97 \pm 159.98$ & $26.34 \pm 3.15$ & $470.00 \pm 0.25$ & $2509.42 \pm 90.39$ \\
\hline Sangareddy & $27.25 \pm 5.96$ & $469.69 \pm 0.26$ & $2385.68 \pm 109.67$ & $26.60 \pm 3.56$ & $469.94 \pm 0.28$ & $2466.83 \pm 68.64$ \\
\hline Ranchi & $26.81 \pm 3.57$ & $469.97 \pm 0.24$ & $2520.59 \pm 178.47$ & $28.79 \pm 2.69$ & $470.01 \pm 0.29$ & $2307.31 \pm 81.68$ \\
\hline Bengaluru & $33.11 \pm 3.41$ & $469.87 \pm 0.37$ & $2003.03 \pm 49.01$ & $33.89 \pm 5.34$ & $469.98 \pm 0.31$ & $1937.89 \pm 92.91$ \\
\hline \multirow[t]{2}{*}{ Mohanpur } & $25.32 \pm 3.19$ & $496.93 \pm 0.22$ & $2651.36 \pm 172.25$ & $28.33 \pm 1.20$ & $469.98 \pm 0.25$ & $2341.99 \pm 63.70$ \\
\hline & \multicolumn{3}{|c|}{ Near future } & \multicolumn{3}{|c|}{ Distant future } \\
\hline Lucknow & $21.80 \pm 3.47$ & $469.97 \pm 0.17$ & $3065.08 \pm 172.81$ & $19.57 \pm 3.15$ & $470.00 \pm 0.21$ & $3382.49 \pm 153.74$ \\
\hline Sangareddy & $25.22 \pm 5.10$ & $469.93 \pm 0.21$ & $2636.98 \pm 136.18$ & $22.55 \pm 3.98$ & $469.98 \pm 0.17$ & $2636.98 \pm 136.18$ \\
\hline Bhubaneswar & $21.96 \pm 7.05$ & $470.02 \pm 0.22$ & $2854.93 \pm 189.17$ & $20.69 \pm 5.59$ & $470.01 \pm 0.17$ & $3170.01 \pm 139.67$ \\
\hline Ranchi & $24.09 \pm 3.15$ & $469.97 \pm 0.24$ & $2758.29 \pm 192.51$ & $21.80 \pm 2.65$ & $469.94 \pm 0.21$ & $3064.72 \pm 150.22$ \\
\hline Bengaluru & $29.8 \pm 3.78$ & $470.08 \pm 0.28$ & $2218.01 \pm 135.25$ & $25.94 \pm 3.01$ & $469.92 \pm 0.25$ & $2535.75 \pm 135 . .39$ \\
\hline Mohanpur & $23.46 \pm 3.07$ & $469.98 \pm 0.22$ & $2885.58 \pm 189.38$ & $20.90 \pm 2.50$ & $469.95 \pm 0.20$ & $3182.29 \pm 145.94$ \\
\hline
\end{tabular}

GT: generation time; GDD: growing degree days; TDD: total degree days

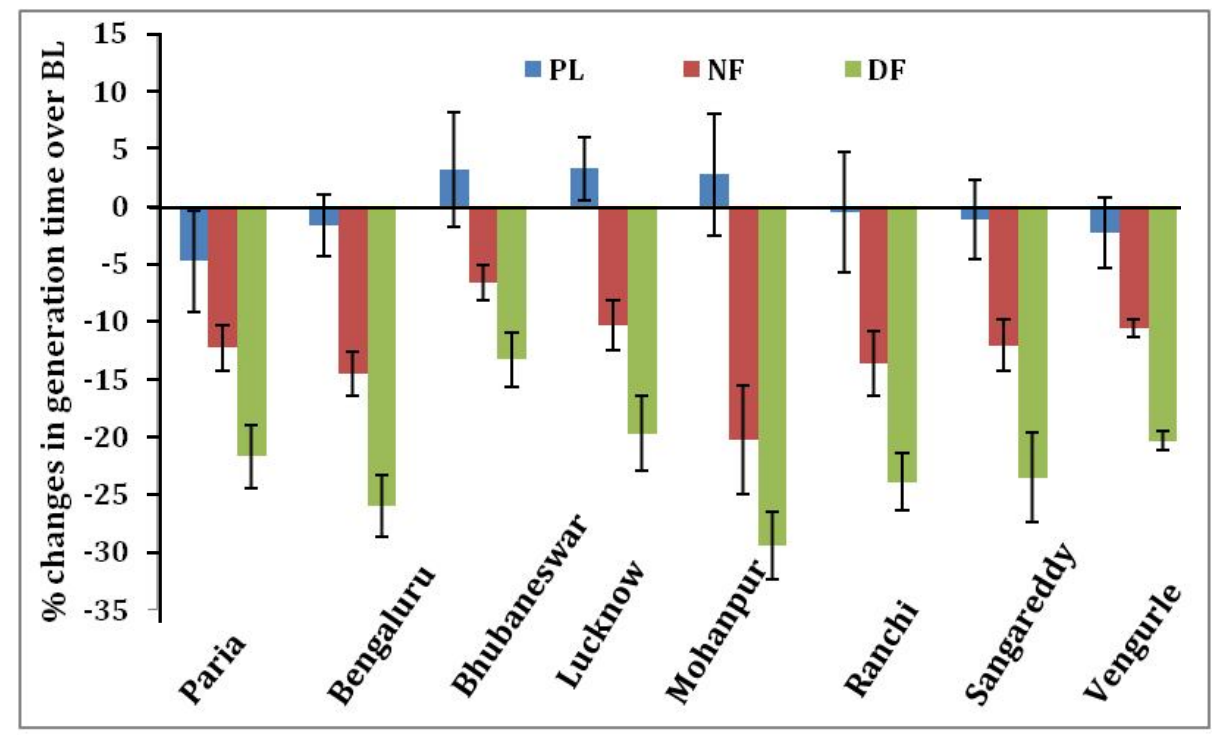

Fig 1: Per cent change in generation time of $B$. dorsalis during mango fruiting season under climate change scenarios

6.59-14.46 per cent in near future and $13.28-29.43$ per cent during distant future across all the regions (Fig. 1). The highest per cent reduction in generation time over baseline is predicted for distant future (29.43\%) at Mohanpur followed by Bengaluru (25.97\%). Analysis of number of generations among climate change scenarios over the present periods using t-test showed that variation was significant $(p=<0.01)$ at all the selected locations except Vengurle and Bengaluru where no significant difference was noticed among base and present period generation numbers (Table 2).

The Mann Kendall (MK) test was applied on a yearly 


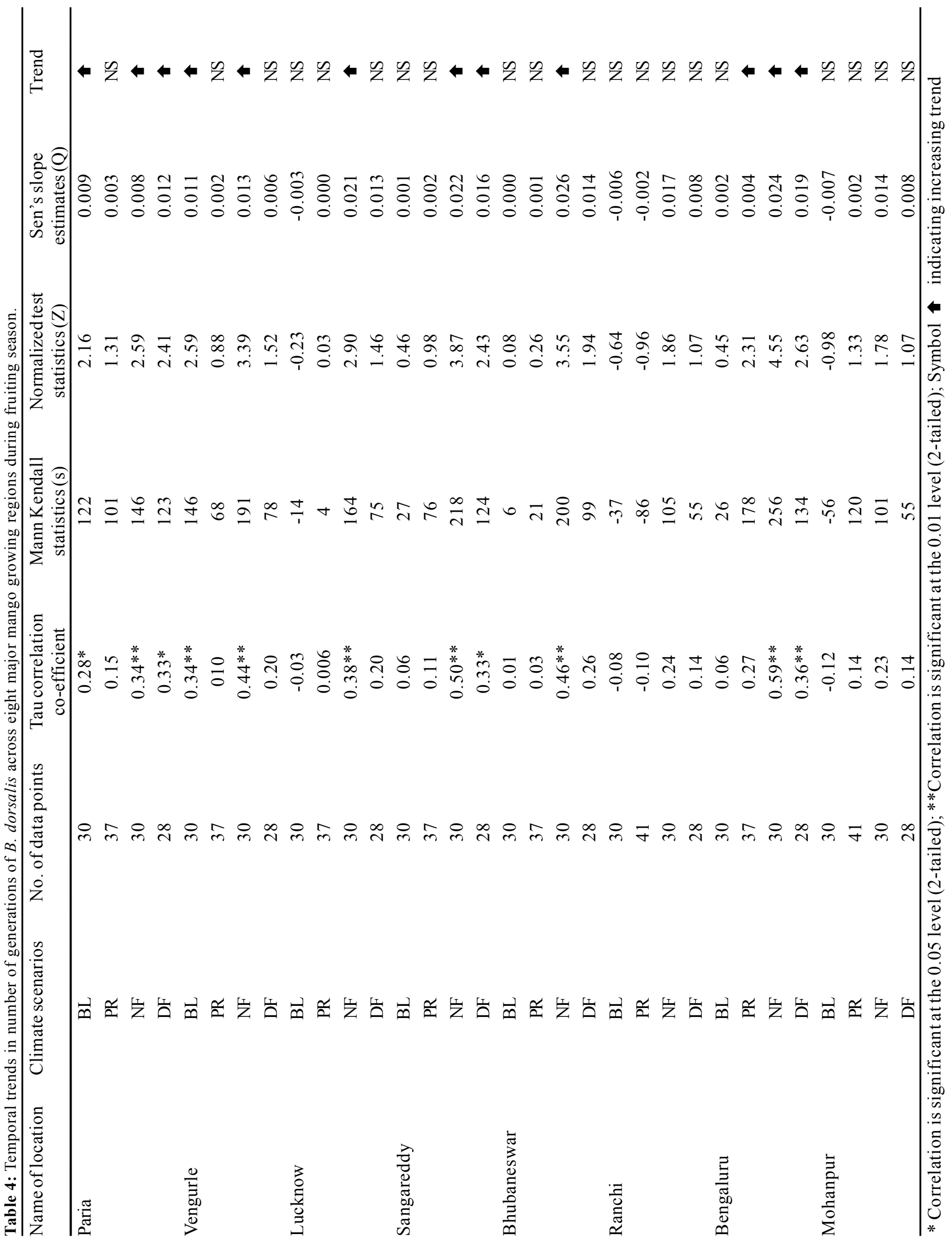


data to detect trends in number of generations of $B$. dorsalis in different climate scenarios and the values of the MannKendall statistic and Sen's slope are presented in Table 4. Non significant temporal variation of $B$. dorsalis was observed during BL and PR periods at all the locations except Paria, whereas significant increasing trend was predicted to occur during base level period ( $\mathrm{p}=<0.05$; Sen's Slope $(\mathrm{Q})=0.009)$. The number of generations of $B$. dorsalis during mango fruiting season for NF periods at Paria, Vengurle, Lucknow, Sangareddy, Bhubaneswar and Bengaluru exhibited significant increasing trends $(p=<0.01)$ with the respective Sen's slope (Q) 0.008, 0.013, 0.021, $0.022,0.026$ and 0.024 whereas, non significant trends were observed for Ranchi and Mohanpur locations. In general, research findings indicate that there would be an increasing trend of number of generations during future climate change scenarios at all the tested locations of mango regions. Similar result of number of generation model fit with time period was observed by Hu et al. (2015) during 2021-2050 in case of brown planthopper, Nilaparvata lugens, in China.

Majority of studies showed that prediction of number of generations, development time and estimation of the sensitivity of impact predictions to differences in geographical locations in relation to temperature could be possible through degree day's models (Srinivasa Rao et al., 2014b; 2015). Present study also brings out the impact of climate change on $B$. dorsalis following similar approaches related above. Increase in the number of generations annually with extreme temperatures in insect species was well known and is a regular phenomenon with gradual increase of temperature as observed in present study.

\section{CONCLUSION}

Present study indicated additional number of generations of $B$. dorsalis on mango fruits as an effect of climate change particularly increased temperatures with an expected aggravated population on mango at majority of major mango growing region of India during future climate change periods. The present results may call for better decision making management strategies in future on mango plant protection. Even though there may be great uncertainty inherent in present single model and scenario combination approach, the results depict a possible highest increase in number generations of the $B$. dorsalis without considering crop phenology, pest phonology and multi-species interactions.

\section{ACKNOWLEDGMENT}

This research work was funded by Ministry of Agriculture, Government of India through National Initiative on Climate Resilient Agriculture (NICRA) project under Indian Council of Agricultural Research (ICAR) (ICARRCER/RC R/E.F./2011/29). The funders had no role in study design, data collection and analysis, decision to publish, or preparation of the manuscript.

\section{REFERENCES}

Briere, J.F., Pracros, P., Le Roux, A.Y. and Pierre, J.S. (1999). A novel rate model of temperature-dependent development for arthropods. Environ. Entomol., 28: 22-29.

Choudhary, J.S., Naaz, N., Prabhakar, C.S. and Moanaro (2016). Genetic analysis of oriental fruit fly, Bactrocera dorsalis (Diptera: Tephritidae) populations based on mitochondrial coxl and nadl gene sequences from India and other Asian countries. Genetica, 144: 611623.

IPCC (2013) Summary for policymakers. In: climate change 2013: the physical science basis. Contribution of Working Group I to the Fifth Assessment Report of the Intergovernmental Panel on Climate Change Cambridge UniversityPress, Cambridge, United Kingdom and New York, NY, USA.

Jarvis, C.H. and Baker, R.H.A. (2001). Risk assessment for nonindigenous pests: 2 . Accounting for inter-year climate variability. Diver. Distrib., 7: 237-248.

Kapoor, V.C. (1993). Indian fruit flies (Insecta: Diptera: Tephritidae). Oxford \& IBH Publishing Co Pvt Ltd, New Delhi. ISBN 81-204- 0745-8.

Kendall, M.G. (1975). Rank Correlation Methods. Griffin, London.

Krishna, Kumar, K., Patwardhan, S.K., Kulkarni, A., Kamala, K., Rao, K. and Jones, R. (2011). Stimulated projections for summer monsoon climate over India bya high-resolution regional climatic model. Curr. Sci., 3: 312-326.

Srinivasa, Rao, M., Rama, Rao, C.A., Raju, B.M.K., Manimanjari, D., Srinivas, K., Maheswari, M. and Ramamohan, I. (2014a). ingen. National Initiative on Climate Resilient Agriculture (NICRA), Central Research Institute for Dryland Agriculture (CRIDA), Hyderabad.

Srinivasa, Rao, M., Rama, Rao, C.A., Vennila, S., Manimanjari, D., Maheswari, M. and Venkateswarlu, B. (2014b). Estimation of number of generations of Spodoptera 
litura Fab. on peanut in India during near and distant future climate change scenarios. Sci. Res. Essays, 9(7): 195-203.

Srinivasa, Rao, M., Swathi, P., Rama, Rao, C.A., Rao, K.V., Raju, B.M.K., Srinivas, K., Manimanjari, D. and Maheswari, M. (2015). Model and scenario variations in predicted number of generations of spodoptera litura fab on peanut during future climate change scenario. PLoS One, 10 (2): e0116762.

Stephens, A.E.A., Kriticos, D.J. and Leriche, A. (2007). The current and future potential geographical distribution of the oriental fruit fly, Bactrocera dorsalis (Diptera: Tephritidae). Bull. Entomol. Res., 97:369-378.

Stonehouse, J.M. (2001). An overview of fruit fly research knowledge and needs in the Indian Ocean region. In
"Proceedings of the second national symposium on integrated pest management (IPM) in horticultural crops: new molecules, biopesticides and environment, Bangalore".

Yamamura, K. and Yokozawa, M. (2002). Prediction of a geographical shift in the prevalence of rice stripe virus disease transmitted by the small brown planthopper, Laodelphax striatellus (Fallen) (Hemiptera: delphacidae), under global warming. Appl. Entomol. Zool., 37: 181-190.

Ziter, C., Robinson, E.A. and Jonathan, N.A. (2012). Climate change and voltinism in California insect pest species: sensitivity to location, scenario and climate model choice. Glob. Change Biol., 18: 2771-2780. 